\title{
Durability of Tyre Rubber Concrete Modified with GGBS and Silica
}

\author{
${ }^{1}$ Sulagno Banerjee, ${ }^{2}$ Aritra Mandal and ${ }^{3}$ Jessy Rooby \\ ${ }^{1}$ Department Civil Engineerieng, Elitte College of Engineering, \\ ${ }^{2}$ Department of Civil Engineering, Techno International Batanagar, \\ ${ }^{3}$ Department of Civil Engineering, Hindustan University, Padur, Chennai, Tamil Nadu, India \\ connect2sulagno@rediffmail.com
}

\begin{abstract}
Disposal of tyre rubber suit a gigantic dilemma in India day by day. Researchers are trying to use waste rubber in civil engineering project from many days back. Crumb rubber replaced fine aggregate is a common practice now a days. Researcher already replaced upto $20 \%$ chipped rubber with coarse aggregate earlier and found that $5 \%$ replacement is optimum but that lack some strength from conventional concrete. In this research programme researcher have tried to minimise that gap by adding extra $5 \%$ micro silica of the weight of cement and have also replaced $40 \%$ cement by GGBS. To check the durability against acid and salt, cubes, cylinders and prisms are casted to test compressive strength, tensile strength, flexural strength after immersing in $5 \%$ by volume of sulphuric acid and $5 \%$ by weight of sodium chloride salt. Water absorption test, mass loss/gain test are also observed after 56 days.
\end{abstract}

Key words: Tyre, rubberized concrete, replacement of coarse aggregate by used rubber, GGBS concrete, chipped rubber concrete, micro silica with cement

\section{INTRODUCTION}

Now a day's, sustainability is the main factor for research. For environment impact researchers had tried to use waste products as much as they can and recycling of waste product is the main key for research. In this particular research programme waste tyre chipped rubber is recycled as coarse aggregate which acts as 5\% replacement of conventional coarse aggregate. For being more eco friendly $40 \%$ cement is replaced by GGBS and extra $5 \%$ micro silica is being added to enhance the strength. To check the durability against acid and salt, cubes, cylinders and prisms are casted to test compressive strength, tensile strength, flexural strength after immersing in $5 \%$ by volume of sulphuric acid and $5 \%$ by weight of sodium chloride salt. Water absorption test, mass loss/gain test are also observed after 56 days.

Objective and past research: Concrete is the most used material in construction liable for the depletion of natural resources and increases the scarcity of the ingredients such as cement, steel and aggregates, consequently, there is a demand for these materials in the commercial sector. Further,mining of river sand causes severe environmental damage by lowering ground water table and disintegration of rock strata causes landslide and earthquake. Engineers are anxious to overcome this problem with other alternatives. Many researchers have attempted to identify the subsidiary use of the traditional materials. Emiroglu et al. (2012) found slump depends on rubber content and gradual decrease in strength with the increase of rubber. El Gammal et al. (2010) tested concrete with $10-25 \%$ crumb rubber replacement along with silica fume and rubcrete. Tayeh (2013) found satisfactory performance against impact load and bending load with increased in percentage of sand replacement by the crumb rubber. Helme et al. recommended 25\% substitution showed compressive strength within allowable range for most applications of concrete of the control mix design. Naito et al. (2013) found unit weight of CRC decreases linearly. Richardson et al. (201 la, b) found concrete strength reduction is an indication of air $\mathrm{void} /$ crumb spacing which offers freeze/thaw protection. Richardson et al. (201 1a, b) concluded addition of 0.5 and $1 \%$ rubber crumb by mass of concrete to replicate levels of air entrainment that will provide freeze thaw resistance. Naik and Siddique (2002) found that it is possible to make relatively high strength rubber concrete using magnesium oxychloride cement which gives better bonding characteristics to rubber and significantly improves the performance of rubcrete. Vadivel and Thenmozhi (2012) found grade of concrete plays the major role in the ductility performance of rubber replaced concrete.

Corresponding Author: Sulagno Banerjee, Department Civil Engineerieng, Elitte College of Engineering, Hindustan University, Padur, Chennai, Tamil Nadu, India, connect2sulagno@rediffmail.com 


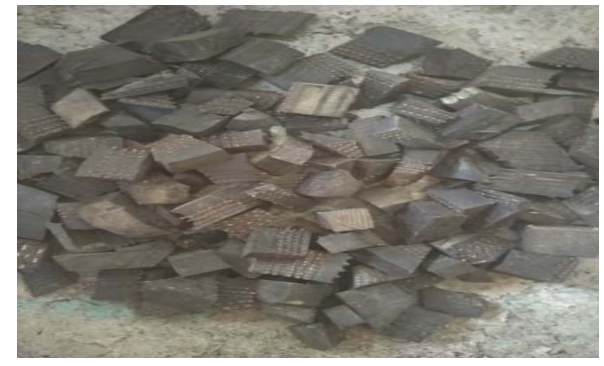

Fig. 1: Rubber aggregate

\begin{tabular}{lll} 
Table 1: Rubber properties & & \\
\hline Parameters & Units & Standard specs \\
\hline Acetone extraction & $\%$ & $5-10$ \\
Ash contetnt & $\%$ & $4 \mathrm{Max}$ \\
Bulk density & $\mathrm{g} / \mathrm{cc}$ & $0.30-0.45$ \\
Sieve analy sis passing 40 $\mathrm{mm}$ sieve & $\%$ & 99 \\
Sieve analysis passing 2 $\mathrm{mm}$ sieve & $\%$ & 1 \\
\hline
\end{tabular}

\section{MATERIALS AND METHODS}

\section{Experimental investigation \\ Materials used}

Cement and aggregates: In the present study ordinary portland cement of grade 43, confirming to IS: 8112-1989 was used for preparing the concrete. The specific gravity of cement was 3.15 .

Fine aggregate: Natural River sand passing through $4.75 \mathrm{~mm}$ IS sieve is used for making concrete. As per IS: 383-1970 Natural River sand was categorized under grading zone 1 . The specific gravity and fineness modulus of sand is found to be 2.65 and 3.05 .

Coarse aggregate: Coarse aggregate was passed through $80 \mathrm{~mm}$ sieve and retained on $4.75 \mathrm{~mm}$ sieve confirming IS: 383-1970 was used for concreting. The specific gravity and fineness modulus of coarse aggregate is found to be 2.695 and 7.7 .

Water: Clean potable water free from suspended particles, chemical substances, biological elements, etc. is used both for mixing of concrete and curing.

Rubber aggregate: This study has concentrated on the performance of a single gradation of rubber prepared by manual cutting (Fig. 1). In this study $5 \%$ of coarse aggregate is replaced by this chipped rubber. The maximum size of the rubber aggregate was $40 \mathrm{~mm}$. The properties of the rubber used as aggregate is given in Table 1.

GGBS: GGBS which is near white in colour is a high quality product, manufactured from a by-product of the
Table 2: GGBS properties

\begin{tabular}{|c|c|c|}
\hline Characteristics & & Values \\
\hline Specific gravity & & 2.90 \\
\hline Bulk density $\left(\mathrm{kg} / \mathrm{m}^{3}\right)$ & & 1220.00 \\
\hline Surface area $\left(\mathrm{m}^{2} / \mathrm{kg}\right)$ & & 416.00 \\
\hline Insoluble residue (\%) & & 0.14 \\
\hline Moisture content (\%) & & 0.14 \\
\hline Loss on ignition (\%) & & 0.19 \\
\hline \multicolumn{3}{|l|}{ Table 3: Mix proportion } \\
\hline $\begin{array}{lc}\text { Grade of concrete } & \text { Target mean strength } \\
\left(\mathrm{N} / \mathrm{mm}^{2}\right)\end{array}$ & W/C ratio & Mix proportion \\
\hline 31.60 & 0.45 & $1: 2.20: 2.73$ \\
\hline
\end{tabular}

Table 4: Result of workability test

\begin{tabular}{lcrc}
\hline Specifications & $\begin{array}{l}\text { Dosage of superp- } \\
\text { lasticizer (weight } \\
\text { of cement \%) }\end{array}$ & $\begin{array}{r}\text { Slump } \\
\text { (mm) }\end{array}$ & $\begin{array}{r}\text { W/C } \\
\text { ratio }\end{array}$ \\
\hline SC (Control concrete) & 0.00 & 100 & 0.45 \\
SCR 5 (Control concrete +5\% Rubber) & 0.50 & 90 & \\
$\begin{array}{l}\text { SGR 0 (40\% GGBS replaced cement } \\
\text { concrete with no rubber and silica) }\end{array}$ & 0.25 & 85 & \\
$\begin{array}{l}\text { SGR 5 (40\% GGBS replaced cement } \\
\text { concrete +5\% rubber +5\% added silica) }\end{array}$ & 0.50 & 95 & \\
\hline
\end{tabular}

steel or iron making industry. In this study $40 \%$ of cement is replaced by GGBS. The physical properties of GGBS sample is shown in Table 2 .

Glenium 51: Glenium 51 superplasticizer is used for higher workability. In this study $0.5 \%$ of cementitious material is used as glenium. It is an admixture of a new generation based on modified polycarboxylic ether.

\section{Typical properties:}

- Aspect : light brown liquid

- Specific gravity : $1082-1142 \mathrm{~kg} / \mathrm{L}$ at $20^{\circ} \mathrm{C}$

- $\mathrm{pH}:$ 6-7

- Chloride content : $=0.10 \%$ by mass

- Alkali content : $=3.0 \%$ by mass

Micro silica: Micro silica is a very fine pozzolanic, amorphous material, a by-product of the production of elemental silicon or ferrosilicon alloys in electric arc furnaces. The specific gravity is 2.63 . It is odourless white coloured powder with a pack density of $0.76 \mathrm{~g} / \mathrm{cc}$. In this study micro silica as $5 \%$ by weight of cement is being extra added.

Mix design (as per IS 10262-2009): Based on the trial mixes the final design mix was prepared for M25 grade of concrete as per IS, 10262:2009. The concrete mix proportions were shown in Table 3 .

\section{RESULTS AND DISCUSSION}

Tests for properties: The workability test, durability against acid and salt were carried out to determine the durability and workability. 

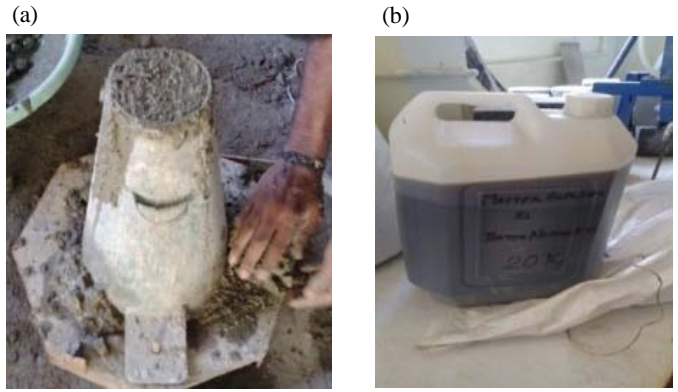

Fig. 2: a, b) Slump test and glenium

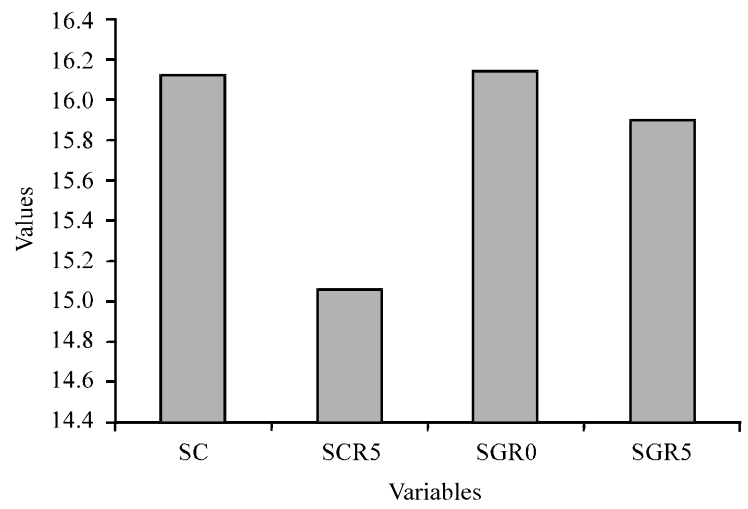

Fig. 3: Compressive strength against acid in $\mathrm{MPa}$ (56 days)

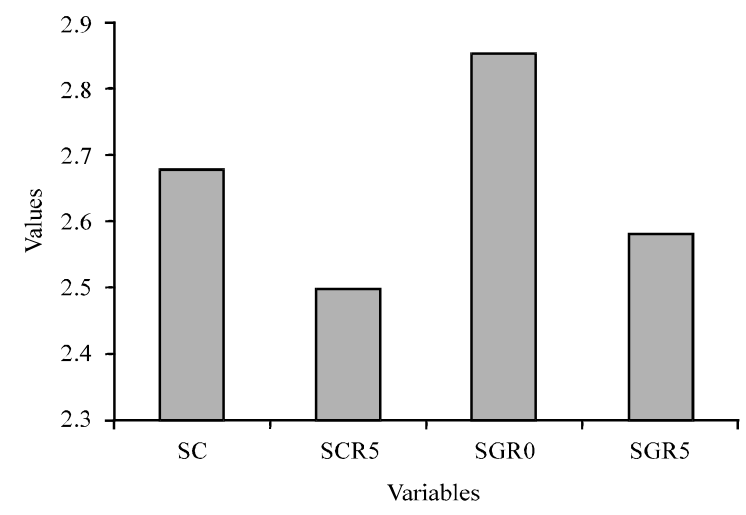

Fig. 4: Flexural strength against acid in $\mathrm{MPa}$ (56 days)

Workability test: Slump test was conducted using slump cone apparatus to determine the workability and it is shown in Table 4 (Fig. 2).

Compressive strength, flexural strength and tensile strength: After immersing in $5 \%$ by volume of sulphuric acid for 56 days, the compressive strength, flexural strength and split tensile strengths of the

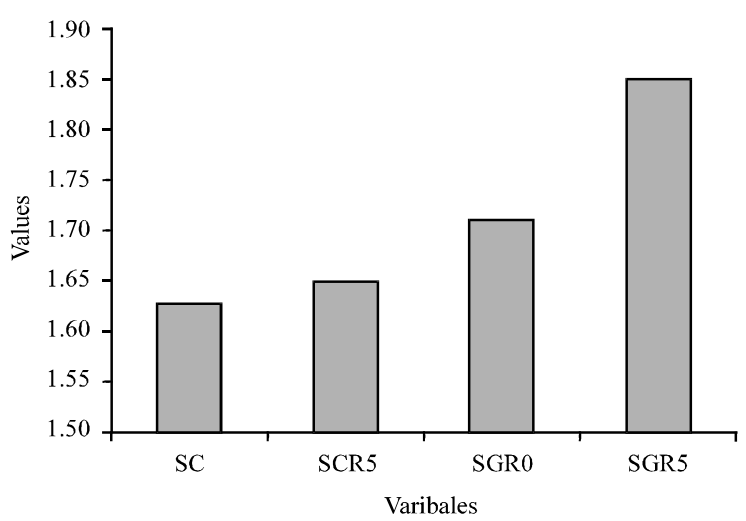

Fig. 5: Split tensile strength against acid in $\mathrm{MPa}$ (56 days)

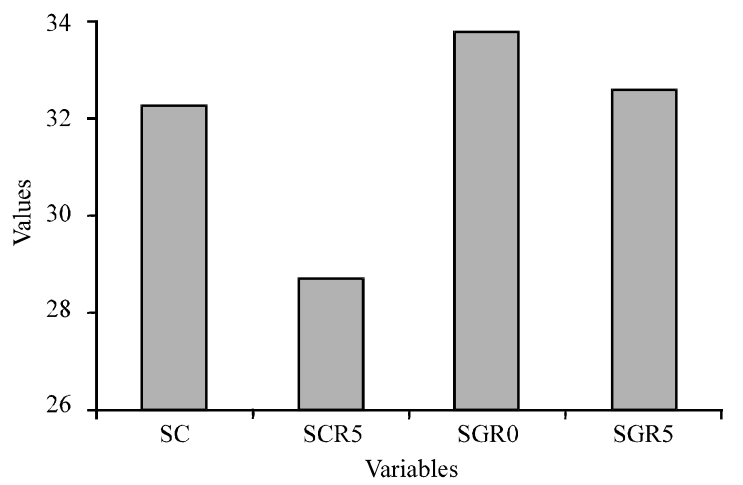

Fig. 6: Compressive strength against salt in $\mathrm{MPa}$

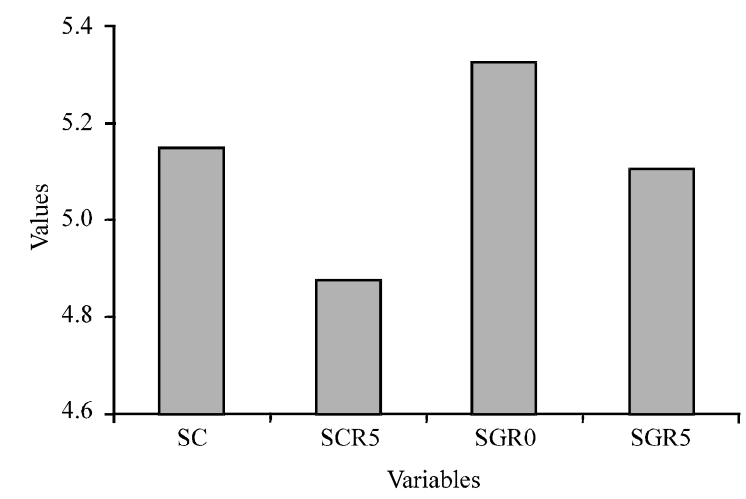

Fig. 7: Flexural strength against salt in $\mathrm{MPa}$

specimens was determined in a universal testing machine of 200 tones capacity and it is tabulated in Fig. 3-7.

Compressive strength, flexural strength and tensile strength: After immersing in $5 \%$ by weight of sodium chloride salt for 56 days, the compressive strength, 


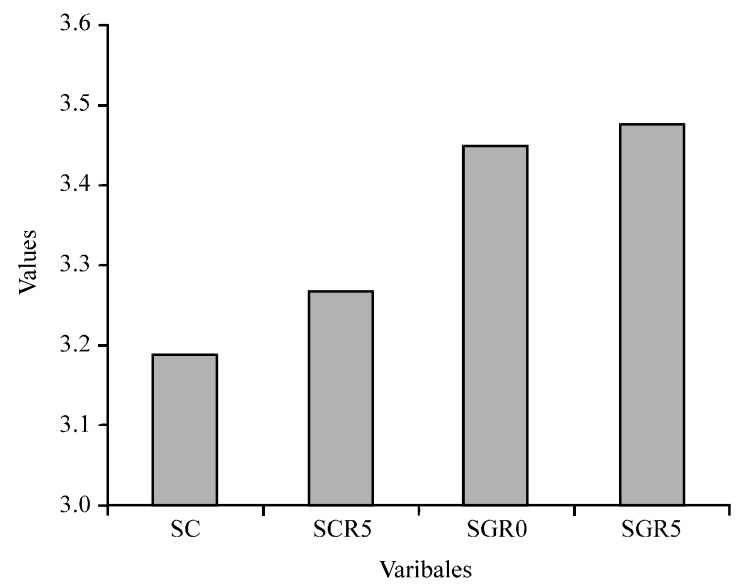

Fig. 8: Split tensile (tensile strength against salt in $\mathrm{MPa}$ )

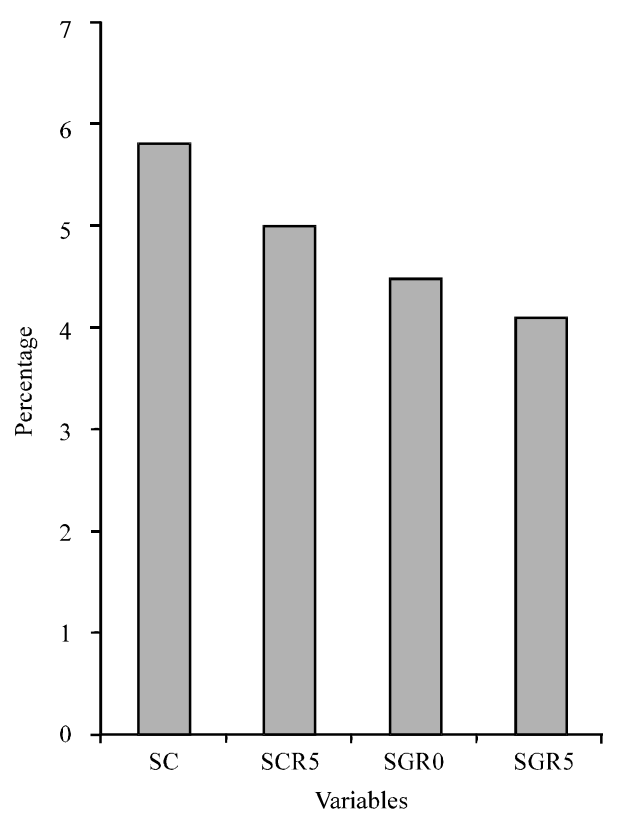

Fig. 9: Percentage of water absorption

flexural strength and split tensile strengths of the specimens was determined in a universal testing machine of 200 tones capacity and it is tabulated in Fig. 6-8.

Water absorption test: The specimens are dried in an oven for $24 \mathrm{~h}$ and at $100^{\circ} \mathrm{C}$ temperature and then placed in a dessicator to cool. Immediately upon cooling the specimens are weighed. Then, they are emerged in water at $23^{\circ} \mathrm{C}$ for $24 \mathrm{~h}$ or until equilibrium. Specimens are removed, patted dry with a lint free cloth and weighed and the result is tabulated in Fig. 9.

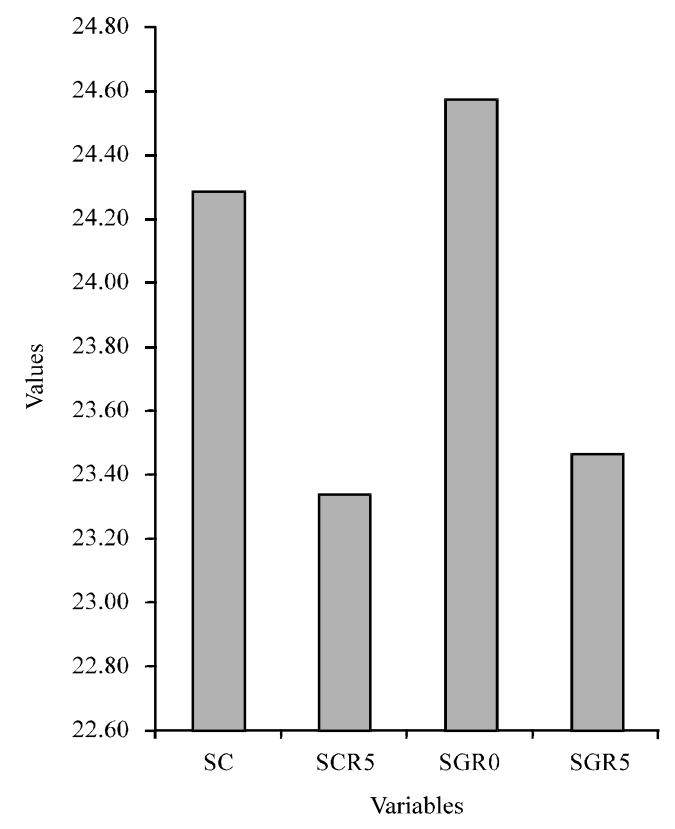

Fig. 10: Unit weight of materials in $\left(\mathrm{kN} / \mathrm{m}^{3}\right)$

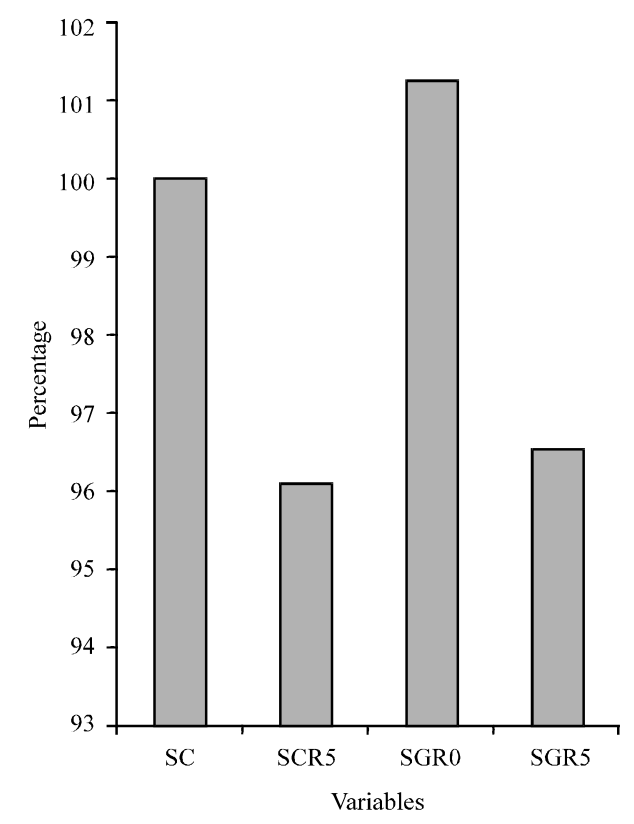

Fig. 11: Reduction in unit weight (taking $\mathrm{SC}$ as $100 \%$ )

Unit weight: The unit weight test is a measure of the weight per cubic meter of freshly mixed concrete and it is the tabulated in Fig. 10 and 11.

Weight loss/weight gained: To conduct this test, 5\% by volume of sulphuric acid and $5 \%$ by weight of sodium chloride were mixed with ordinary potable 


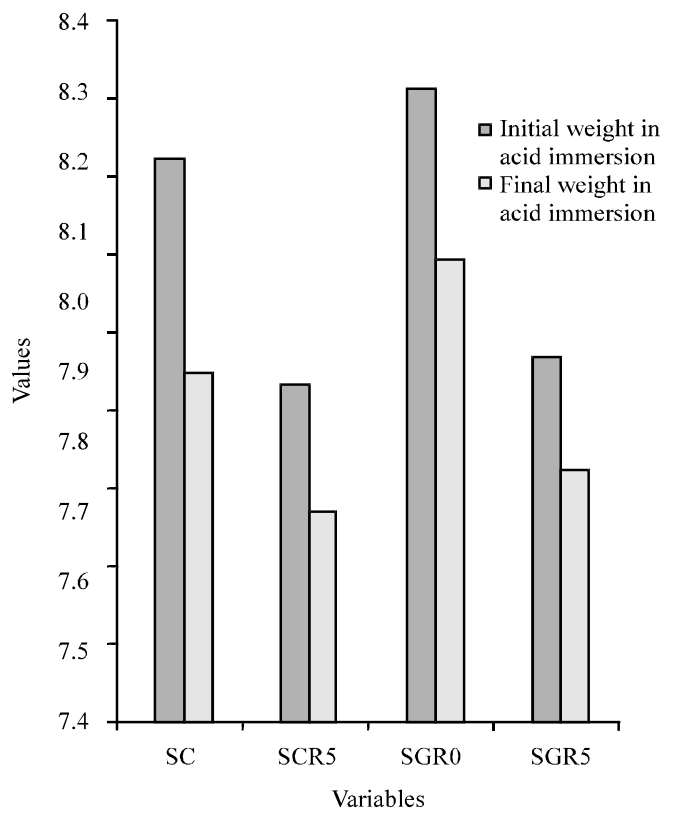

Fig. 12: Comparision of weight of cubes immersed in acid

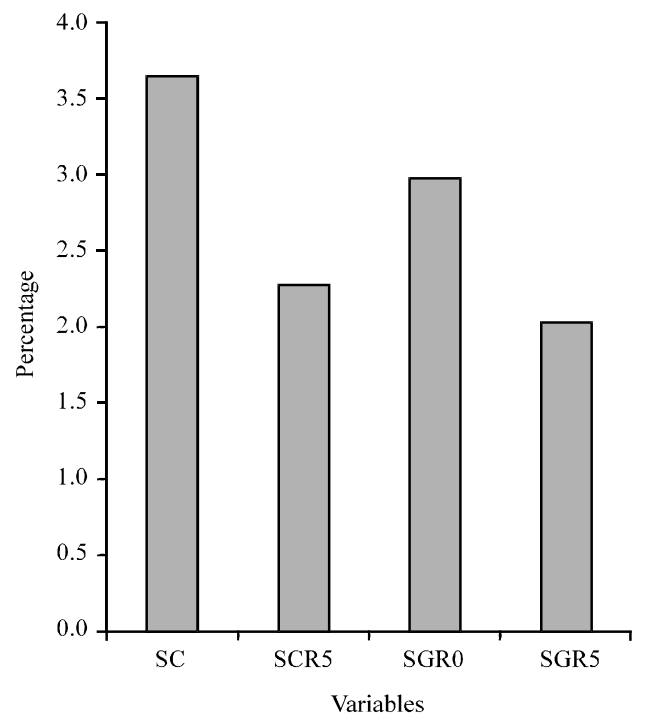

Fig. 13: Percentage of weight loss in acid solution $\left(\mathrm{H}_{2} \mathrm{SO}_{4}\right.$ immersion)

water. The cubes which were cured for 28 days were then immersed in these solutions. The cubes were then taken out from this solution after 56 days of exposure to solution and were surface dried. The surface of cubes was cleaned, scrubbed and final surface dry weights and percentage of increase and decrease in weight were found and tabulated in Fig. 12-15.

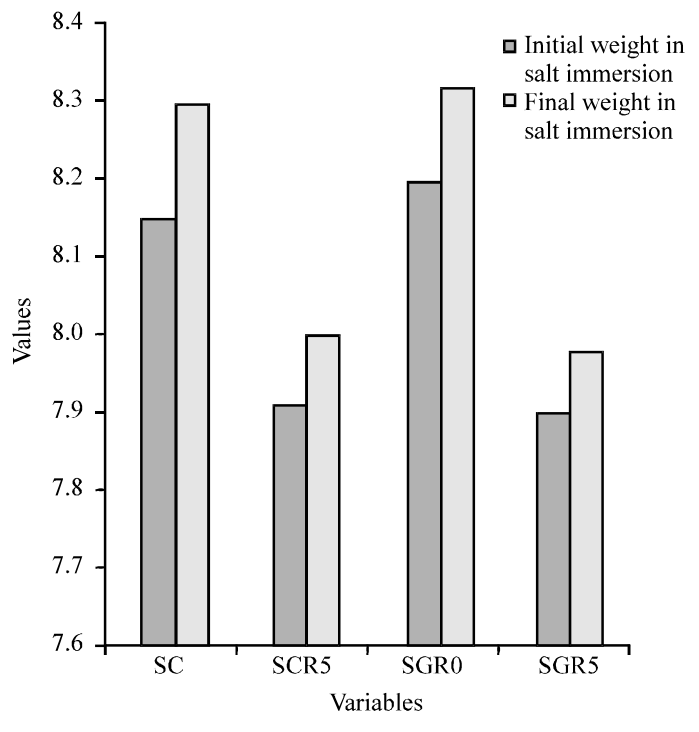

Fig. 14: Comparision of weight of cubes immersed in salt

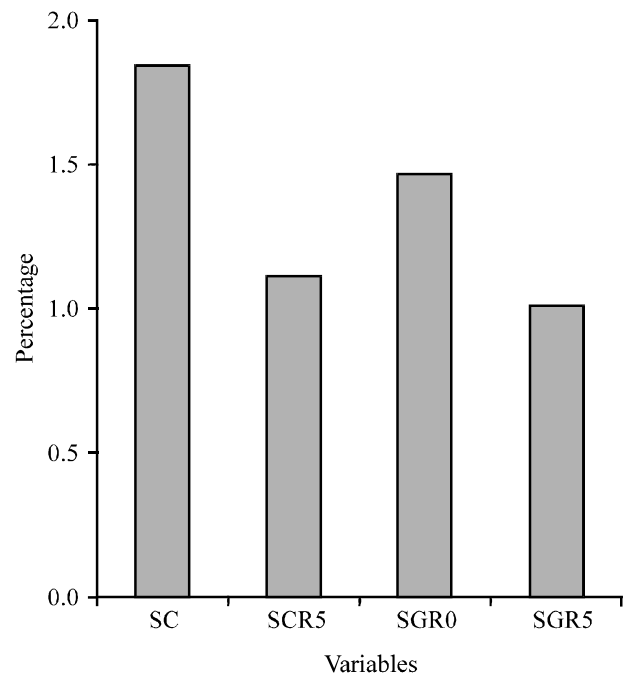

Fig. 15: Percentage of weight gain in salt solution $(\mathrm{NaCl}$ immersion)

\section{CONCLUSION}

When rubber is added the mixture becomes dry and so, slump value decreases and hence, we have to add superplasticizer inorder to get the desired slump value. After 56 days immersion in acids and salts, the decrease in compressive strength and flexural strength in rubber concrete is almost similar to that of conventional concrete and the residual strength value is almost the same for both concretes. After 56 days immersion in acids and salts, the decrease in tensile strength in rubber concrete is almost similar to that of conventional concrete and the 
residual strength value of rubber concrete is a bit more than that of conventional concrete. Weight loss in acids is almost $1.6 \%$ less in rubber concrete than that of conventional concrete. Weight gain in salts is almost $0.75 \%$ less in rubber concrete than that of conventional concrete. Durability study found that the voids of concrete were filled with inert rubber particles that reduce the permeability and increase the resistance against severe attacks such as acids and chlorides. Hence, rubber concrete is durable than the conventional concrete. Unit weight of rubber concrete is much lower $(3.70 \%)$ than conventional concrete which will reduce the dead load of self weight. Rubber concrete being less permeable, water absorption is lower in rubber concrete.

\section{REFERENCES}

El-Gammal, A., A.K. Abdel-Gawad, Y. El-Sherbini and A. Shalaby, 2010. Compressive strength of concrete utilizing waste tire rubber. J. Emerging Trends Eng. Appl. Sci., 1: 96-99.

Emiroglu, M., S.Y.O. Kestemur and M.H. Kelestemur, 2012. Bond Performance of Rubber Particles in the Self-Compacting Concrete. In: Bond in Concrete 2012-Bond in New Materials and Under Severe Conditions, Cairns, J.W., G. Metelli and G.A. Plizzari (Eds.). Brilliant Creations Publishing Inc., Quezon City, Philippines, pp: 779-785.
Naik, T.R. and R. Siddique, 2002. Properties of concrete containing scrap tire rubber-an overview. Master Thesis, Department of Civil Engineering and Mechanics, University of Wisconsin-Milwaukee, Milwaukee, Wisconsin.

Naito, C., J. States, C. Jackson and B. Bewick, 2013. Assessment of crumb rubber concrete for flexural structural members. J. Mater. Civ. Eng., 26: 04014075-04014075.

Richardson, A., K. Coventry and J. Pienaar, 2011b. The potential for achieving freeze/thaw protection in concrete through the addition of rubber crumb. Built Nat. Environ. Res. Pap., 4: 110-126.

Richardson, A., K. Coventry, U. Dave and J. Pienaar, 2011a. Freeze/thaw performance of concrete using granulated rubber crumb. J. Green Build., 6: 83-92.

Tayeh, A.I., 2013. Effect of replacement of sand by waste fine crumb rubber on concrete beam subject to impact load: Experiment and simulation. Civ. Environ. Res., 3: 165-172.

Vadivel, T.S. and R. Thenmozhi, 2012. Experimental study on waste tyre rubber replaced concrete-an ecofriendly construction material. J. Appl. Sci. Res., 8: $2966-2973$ 